\title{
Smart charging impact on electric vehicles in presence of photovoltaics
}

\author{
Khaled Hajar*+, Baoling Guo*, Ahmad Hably*, Seddik Bacha* \\ Univ. Grenoble Alpes, CNRS, Grenoble INP*, \\ GIPSA-Lab, G2ELAB, 38000 Grenoble, France \\ *Institute of Engineering Univ. Grenoble Alpes \\ +Université de technologie et de sciences appliquées Libano-française Deddeh-Lebanon
}

\begin{abstract}
The emergence of electric vehicles (EVs) promises to be the turning point of sustainable energy and, in particular, renewable energy production in the world. EV Charging will generate substantial extra demand for electricity. Renewable energy, including solar and wind power, can be met in the grid technically and economically. Recent studies have shown that smart charging of EV can increase the synergy between photovoltaics (PV), electrical transmission and electricity usage, resulting in technological and economic advantages. Given the increasing emphasis on this area, this analysis summarizes an overview on smart charging studies taking into account PV power output and consumption of electricity.
\end{abstract}

Keywords: Electric vehicles, plug in electric vehicles, V2G, RESs, EV charging program, charging station. ${ }^{1}$

\section{INTRODUCTION}

Climate change, air pollution and peak oil demand are the biggest threats facing the humanity and its societies. These threats are directly linked to the electric power generation and the transportation sectors who contribute for more than $25 \%$ of world demand for primary energy [1]. In combination with EVs and clean energies, development of the transport and electricity markets will drastically reduce the world's reliance on fossil fuels, and the resulting emission of greenhouse gases [2]. Although renewable energy such as solar and wind are effective only when the wind blows or the sun shines, natural gas plants may increase their energy production to meet the demand. Several techniques were developed to handle supply variations in different time scales, including storage, dispatching loads (or demand-response) and alternative power generation. The wide deployment of EVs will also be an essential aspect of clean technology penetration with existing power grids. EVs with an electric grid connectivity will help all these approaches.

The objective of this paper is to review the main literature on EV's effect on the grid with a special attention on renewable energy integration. The paper is organized as follows: Section II illustrates the smart charging definition, section III describes the interaction between the grid, PV and EV, then section IV discusses the EVs charging impact, sections $\mathrm{V}$ and VI specify the main goals of smart charging and the control configuration respectively. Next, section VII provides EVs spatial configuration, followed by an optimization algorithms summary in section VIII. Finally,

\footnotetext{
${ }^{1}$ This paper is supported by aVEnir project of the PIA operated by ADEME.
}

a discussion on future works and the challenges on EV charging system is given.

\section{SMART CHARGING SYSTEM}

Smart charging uses vehicle-grid interface technology to control EV loads. This is achieved by reacting to price signals, automatic charging control while meeting the needs of consumers for the availability of vehicles. It requires adjusting such charging intervals in time or adjusting power under constraints (e.g. connectivity capability, consumer requirements, local energy output in real time). Thus, smart charging is a way to customize the charging process according to the constraints of the distribution system and local availability of renewable energy. Charging and discharging EVs in an intelligent way can prevent creating stress in the local distribution grid and can also offer resources to fulfill flexibility needs in general. Smart EVs charging/discharging may help to minimize sustainable intermittent energy, increase its local use, prevent investment in peak power production. As grid-connected storage units, EVs provide to the system a wide variety of services. EVs could modify their charging behaviors to decrease peak demand and help real-time grid balancing using charging levels modification. Smart charging can offer advantages to various parts of the energy grid depending on the way of charging/discharging is controlled, from relationships between various parties involved, legislative restrictions and trade models. As shown in fig. 1, the main actors are:

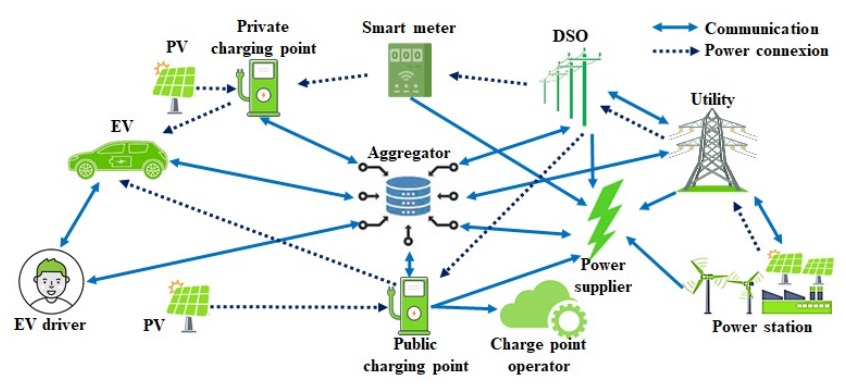

Fig. 1: Smart charging actors

- EV: Electric vehicle.

- EV user: Responsible for the plugging in the vehicle.

- Public charging point: It is mounted on the road or on a particular charging station. 
- Private charging point: Charging is only accessible at home or at an office building.

- Charge Point Operator: Manages public charging point operations, including supervision, maintenance and billing operations.

- Distribution System Operator: Controls the distribution network at low voltage and effectively regulates the network loads.

- Power station: Operates electricity-generating power, such as fossil, hydro-power, or wind and solar farms.

- Power supplier: Energy suppliers for the buying and selling of power on wholesale markets.

- Aggregator: Agent that combines the controls of multiple EV charging to optimize the fee on the basis of market prices distribution.

\section{EV, PV AND GRID INTERACTION}

In this section a general overview of grid energy use, PV production, and EV charging is described. Further discussed and explored is the relationship between these three elements and how smart charging will lead to stronger synergies. Several variables identify electricity usage, such as human lifestyle, industrial activities and climate conditions [3]. However, the trend is strongly related to human behavior regarding daily load shapes [4].

PV transforms solar-incident irradiation to electric power. The production of electricity differs based upon location, direction and relies primarily on the irradiation during the year [5]. The daily mobility routine or activity schedules of the vehicle's users define uncontrolled EV charging profiles [6]. The uncontrolled charging of EV describes that its battery begins to charge as soon as it is plugged in at the maximum available power. If this supplementary energy demand meets the peak power requirement, the massive passive charge would bring considerable costs to the power grid. This includes investment in additional power generation and network capacity to address higher demand. However, smart charging may be used to shift the load in response to the power system needs. It may decrease costs by growing the efficient use of coal plants or by exploiting renewable. Several power grids have already higher load or usage factors leading to high late afternoon demand and low demand from midnight to dawn. The demand profile would potentially experience drastic increases as $\mathrm{PV}$ production and $\mathrm{EV}$ demand are rising. Therefore, new approaches for PV and EV management systems are expected in future. For example, in residential areas the occupancy of EVs available during working hours (and solar energy production peaks) is relatively small, meaning uncontrolled EV charging does not help to increase self-consumption of PV [7]. According to its long stationary period, the temporal flexibility of EVs enables the control and scheduling of smart EV charging. Smart charging systems allow EVs to connect efficiently with $\mathrm{PV}$ and/or energy usage by programming EVs to enable charging when the output of PV is high or charging when energy demand is low. Vehicle to Grid (V2G) provides new incentives in the area of smart charging by adding auxiliary utilities such voltage control [8] and frequency regulation [9]. Some of the challenges in implementing intelligent control are the inevitable variation in PV production, power load, versatility patterns, uncertainties in EV load, variables loading events (plug-in duration and state of charge (SOC), etc.).

\section{EVS CHARGING IMPACT}

\section{A. Grid infrastructure}

Fast charging is a problem for the development of grid infrastructure. The more power needed from the distribution grid, the more capacity is required. Furthermore, this power must be supported by local charging station, cables and EVs. All are technically viable, but are accessible at a price. At least according to the following criteria the scope of grids (for cables and transformers) which must be invested in a defined location:

- Load characteristics: In places where electrical heating shares are large (thus contributing to higher grid reinforcement), for example, the impacts of unregulated EV charging would be greater. However, where smart charging is being used for such areas, it would be used on lower grid improvements than in locations where electric heating is not required, because regional grids have a greater scale.

- Congestion: For example before EV installation in the local distribution network.

- Low voltage generation connected resources: Smart charging might encourage the introduction of high solar PV shares linked to low voltage, while EVs might raise the burden on local grids in areas without PV or with very small solar PV shares.

- Grid regulations and limits: National grid codes specify both voltage and frequency constraints which distribution system operators must comply with network strengthening expenditure when these specific constraints are violated by EV charging.

\section{B. Electricity demand and capacity}

If EVs were charged at the same time uncontrollably, the peak demand on the grid could be increased, leading to overload the distribution grid. This overload requires the need for capacity improvements. Dependent on energy system mix, grid type and penetration of EVs have various possible impacts. If not handled with smart charging, the effect on local distribution grids can be significant including: increase in thermal load, degraded voltage, increased loss voltage and asymmetry, decreased transformer life [45], and increased harmonic distortion due to chargers, with likely higher power disturbances. A deeper understanding of these future impacts is needed. However operators face several uncertainties: EV charging arbitrary time and space [46], variable battery SOCs, vehicle enforcement [47], variability in household loading, and load distribution, etc. If increased 
demand does not spread smartly, the effect on high demand will be even greater [48]. Thus, smart charging is vital to resolve all these issues.

\section{SMART CHARGING MAIN GOALS}

Smart charging means connecting charging points between users and operators using an smart EV charge management method to avoid overloading and/or destabilizing the grid. Balancing the grid with intelligent charging gives benefit to many different parties from the operator to the consumer. Smart charging helps EV, service provider and charging operator to communicate and thereby automate charging by opening paths to data connections. The key targets of EV smart charging with PV generation and electricity usage are discussed in this section.

\section{A. Increasing profits}

Maximizing profit from charging services is a core interest in charging facilities and aggregators. Thus, it is necessary to reduce operational costs and optimize revenues [14], [17]. One strategy to improve the revenues of charging providers is to reduce energy purchase in high-priced periods like peak-hours, from energy providers. It may also allow the charging supply to reach their financial goals for renewable energies [14], [15]. Energy suppliers may also raise their profits through their involvement in auxiliary and energy exchange markets, in particular through V2G networks [16].

\section{B. Reducing energy's cost}

EV owners benefit directly from smart charging intended to reduce its energy costs. Smart charging schemes have been researched and built to minimize energy costs involving PV systems in [18], [19].

In a system with dynamic electricity prices, the charging costs might vary. In this scenario, electricity prices are more certainly higher at peak hours than at off-peak hours. Charging in public areas can have a range of billing schemes such as hourly level, kWh and membership fees [20].

\section{Increasing PV use}

The environmental effect of an EV relies significantly on the main source of energy used to charge the battery by the grid [13]. Because solar power is not a dispatched energy source, the load dynamics can not be followed and hence the PV energy usage is generally limited. Instead, versatile loads must be managed to increase the usage of PV resources, particularly if there energy storage systems don't exist [21]. Smart charging allows EVs as flexible load which can be moved and regulated in time so that they can be used for load balancing and maximizing the efficient use of PV power [22], [23].

\section{Balancing load}

Both the use of energy and the storage of power are related to human behavior. Therefore, in uncontrolled charging, peak power consumption and demand for charging would generally correlate. V2G, by either selling back electricity or limiting its charging rate, communicate with the grid and sell demand-response services [24]. However, EVs will control the grid back in standby mode, which is useful for increasing stability, peak shaving and power balancing.

\section{CONTROL CONFIGURATIONS}

EV Smart charging can be divided into two types, depending on control configuration: centralized and decentralized charging. The charging time (time of use) and the price level of an EV fleet are calculated by a central unit called aggregator when charging EV with centralized control. The aggregator collects all data concerning EV charging such as locations of EVS, SOC, anticipated departure times and other charging specifications from the users to determine the charging schedule for the EVS [25]. Energy is priced at various levels every day, is an efficient way of changing demand for energy and works well to encourage EV charging. Prices can be chosen according to energy and network needs, however, efficiency depends on the level of price complexity and commitment of EV's user.

Instead of regulated control by a central unit, decentralized smart charging operates at the EV level. Power charging can be regulated directly by a system operator or provider of energy (DSO), or by an aggregator that can be linked to both the charge point and the energy market. It will offer better value commodities and therefore render the electricity sector more profitable.

\section{SPATIAL CONFIGURATIONS}

Smart charging strategy at different places is restricted by the charging period and features of EVs at different locations [26]. The following subsections discuss smart charging in residential buildings, non-residential buildings, and public charging stations. Each station commonly has a distinguishable load demand, where the non-residential station is charged at workstations [35], schools and universities in an early morning.

\section{A. Residential buildings}

The flexibility of EV charging is high at residential buildings. In addition, EV charging during inactive parking at the residential buildings offers a convenience to the EV owners as the EVs will likely be fully charged in the morning before the first trip of the day. Smart charging of EVs can be designed to fill the valley of the typical household load. From the perspective of the residential grid operators, this is one of the most relevant charging schemes as it will reduce grid losses and voltage fluctuations [32]. However, matching EV charging with on-site PV generation is limited by the low fraction of EVs parked at residential buildings during the day when the solar power production is high. 


\section{B. Non-residential buildings}

Since most of the EVs are not at home during daytime, they are either parked in non-residential buildings or driving. Thus, the potential of smart charging in non-residential buildings during these hours is high. Non-residential buildings include workplaces and commercial and public buildings. The benefits of smart charging in non-residential buildings can vary as the load profile could be different depending on the type of the building (workplaces [36],commercial buildings [34], schools and universities [33]). In contrast to smart charging at residential buildings, smart charging at non-residential buildings might benefit more from a combination with solar power production, since when building occupancy is high during daytime, the building energy demand is also high.

\section{Charging stations}

In contrast to residential buildings and non-residential buildings, a charging station as a single unit has a load curve that only depends on the EV charging load, and, hence, the mobility pattern of EV users such parking stations [28]. Smart charging are mostly motivated by financial objectives for their owners [12]. With management schemes at charging stations, EVs can provide better services such as ancillary services to TSO, DSO, and energy storage services for renewable power producers, which increase the revenue of the charging stations. Moreover, equipping charging stations with PV systems has become more common as the coupling of the two technologies can improve technical, economic and environmental performance of EVs.

\section{OPTIMIZATION ALGORITHMS}

Smart charging strategies are designed to accomplish the goals mentioned in section $\mathrm{V}$ using optimisation algorithms which is discussed in this section. A real-time rule-based algorithm for the management of EV charging stations in DC microgrid is simulated under MATLAB/Simulink which presents a reliable performance in terms of precise control [39]. Authors of [42] use a combination of deterministic and rule-based approaches for implementing energy storage management in the PV-integrated EV charging station which shall reduce EV charge cost using a wholesale energy pricing system. A peak load minimization in an educational building equipped with a PV system and an ESS uses rule based algorithm for priority charging [43].

Authors of [63] provide a new optimization paradigm to achieve computational scalability based on the alternative multiplier path approach, which enables the optimization process to be spread through several cores.

Linear programming (LP) is a commonly used method of optimizing EV charging. In [28] authors use LP to simultaneously maximize the number of EVs selected for charge and to minimize the electricity bill paid to the utility grid. LP approach in [55] is used to achieve an ideal charging/discharging rate of each EV for each scheduling cycle subject to the parking station installation capacity.
A scheduling EVs charging/discharging model for implementing in an intelligent parking lot where the technical and economical aspects of EVs charging/discharging are taken into account is proposed in [49]. A smart charging method in [50] that minimizes the battery aging for a large number of electric bus fleet. The key goal of the charging station is to reduce the overall cost of energy trading with various energy entities using mixed integer programming (MIP) during a day by appropriately selecting the amount of energy that it needs to share with each vehicle and other sources at any moment [29]. A mixed integer linear programming (MILP) in [12], [31] minimizes the annual cost of the fast charging station, including operating cost of PV and energy storage, cost of purchasing energy. the result shown in [36] is able to minimize charging cost substantially, while rising PV self-use and decreasing significantly the energy consumption from the grid. Mixed integer second order cone programming is used in [38] with a model for the combined installation of EV charging stations and distributed generation services, during which the $\mathrm{V} 2 \mathrm{G}$ role of EVs is assumed to be comprehensive.

Dynamic programming (DP) is used [51] for a hierarchical management scheme for power loads for EV charging within a distribution network while reducing energy prices and meeting supply constraints. In [52], DP is used to reduce the computation strain by means of a planned aggregate battery model. In [53] a discuss of energy management strategies for various charger types of EV charging stations is presented. The optimum charge start time of each EV is calculated, taking into account both the energy price in real time and the unpredictable potential charge demand. DP in [54] allows for the optimum charge schedule for EVs to be identified so that all supply and demand-based rates of energy and costs can be reduced taking account of the multiple driving habits of each driver.

Quadratic programming (QP) is used in [37] to solve the problem of optimal power flow in a fully decentralized distribution network with massive penetration of PV and EV. Optimization model under QP is used in [56] to decrease the total grid power for the utilities and performs the EV user's smart charging/discharging management. Authors in [57] offer an integrated charge policy for a fleet of electric buses focused on charging scheduling management and power modulation so the optimum charging approach minimizes charge costs and load shifts by means of QP.

Metaheuristic programming (MP) is more effective solution to the problem of optimisation and a higher level strategy, especially where some data is unknown [58]. MP does not guarantee a global optimal solution compared with convex mathematical optimization algorithms, but the method of calculation can be faster [58]. Several MP for the intelligent charging of EVs with either PV generation, energy consumption or both have been proposed.

Robust optimization (RO) also tackles problems of optimization with instability in its variables. A robust multiobjective scheduling model for energy, presented in [60], 
operating and maintenance costs, and solves the model in the worst possible situation in order to maintain a highly stable system, as well as to minimize environmental costs. A formulation under RO in [61] is used to allow EVs to track uncertainty and schedule their capacity to control and to optimize income within the performance-based compensation scheme.

\section{CONCLUSION AND FUTURE WORKS}

Due to the expected acceleration of electrification in transport sector, technological innovation which allows increased battery sizes and the continued utilization of smart charging capabilities for the $\mathrm{V} 2 \mathrm{X}$ and charging infrastructures $\mathrm{EV}$ potential integration between today and 2030/2050 will increase significantly. At the same time, many challenges will slow down the ability to materialize this increasing potential. The shortage of charging infrastructure is now one of the key obstacles to EV activity.

The vehicle grid integration strategies should be introduced through the use of EVs to reduce not only the effect of this extra load on the power system, but also to explore the synergies between EVs and renewable on the system, thus creating the need for greater flexibility. Smart charging must be enabled by effective market design and automatic control, following trends of renewable energy generation.

In certain areas, even though EV are uncontrolled charging, since the wind can blow more at night or evening, when the EV appear to charge, wind output profiles may often well fit EV charge profiles. The gradual advantages of smart charging would therefore be especially important in solar systems. Increased solar share may be implemented on the system level and the local grid levels by shifting the charging to improved solar PV generation and introducing V2G, eliminating the need to invest in distribution grid. In place to enable real world validation of research, growth and advancement carried out in the field, areas with high high local penetration of distributed generation (mainly from PV systems) that have a high local potential for synergies with smart-charged EVs should be further optimized.

\section{REFERENCES}

[1] Moriarty, P., and Honnery, D. (2016). Global transport energy consumption. Alternative energy and shale gas encyclopedia, 651-656.

[2] Bhatti, A. R., Salam, Z., Aziz, M. J. B. A., Yee, K. P., and Ashique, R. H. (2016). Electric vehicles charging using photovoltaic: Status and technological review. Renewable and Sustainable Energy Reviews, 54, 34-47.

[3] Thomas F. Sanquist, Heather Orr, Bin Shui, Alvah C. Bittner, Lifestyle factors in U.S. residential electricity consumption, Energy Policy, Volume 42,2012.

[4] Bonnie Wylie Pratt, Jon D. Erickson,Defeat the Peak: Behavioral insights for electricity demand response program design,Energy Research and Social Science, Volume 61,2020.

[5] Hajar, K. (2017). (Doctoral dissertation).

[6] K. Qian, C. Zhou, M. Allan and Y. Yuan, "Modeling of Load Demand Due to EV Battery Charging in Distribution Systems," in IEEE Transactions on Power Systems, vol. 26, no. 2, pp. 802-810, May 2011.

[7] Quentin Hoarau, Yannick Perez, Interactions between electric mobility and photovoltaic generation: A review, Renewable and Sustainable Energy Reviews, Volume 94, 2018.
[8] Gamboa G, HamiltonC, Kerley R, Elmes S, Arias A, Shen J, et al. Control strategy of a multi-port,grid connected,direct-DC PV charging station for plug-in electric vehicles. In: Proceedings of IEEE energy conversion congress and exposition(ECCE);2010.p.1173-77.

[9] Liu, N., Chen, Q., Liu, J., Lu, X., Li, P., Lei, J., Zhang, J. (2014). A heuristic operation strategy for commercial building microgrids containing EVs and PV system. IEEE Transactions on Industrial Electronics, 62(4), 2560-2570.

[10] Sheng, S., Hsu, C. T., Li, P., Lehman, B. (2013, June). Energy management for solar battery charging station. In 2013 IEEE 14th Workshop on Control and Modeling for Power Electronics 8(11), 13265-13283.

[11] Odkhuu, N., Lee, K. B., A Ahmed, M. Kim, Y. C. (2018). Optimal energy management of V2B with RES and ESS for peak load minimization. Applied Sciences, 8(11), 2125.

[12] Yao, L., Damiran, Z., Lim, W. H. (2017). Optimal charging and discharging scheduling for electric vehicles in a parking station with photovoltaic system and energy storage system. Energies, 10(4), 550.

[13] Yuksel T, Tamayao MAM, Hendrickson C, Azevedo IM, Michalek JJ. Effect of regional grid mix, driving patterns and climate on the comparative carbon footprint of gasoline and plug-in electric vehicles in the United States. Environ Res Lett 2016;11(4):044007.

[14] Liu, L., Kong, F., Liu, X., Peng, Y., Wang, Q. (2015). A review on electric vehicles interacting with renewable energy in smart grid. Renewable and Sustainable Energy Reviews, 51, 648-661.

[15] Ghofrani, M., Arabali, A., Ghayekhloo, M. (2014). Optimal charging/discharging of grid-enabled electric vehicles for predictability enhancement of PV generation. Electric Power Systems Research, 117, 134-142.

[16] K. Chaudhari, A. Ukil, K. N. Kumar, U. Manandhar and S. K. Kollimalla, "Hybrid Optimization for Economic Deployment of ESS in PV-Integrated EV Charging Stations," in IEEE Transactions on Industrial Informatics, vol. 14, no. 1, pp. 106-116, Jan. 2018.

[17] Jin, C., Tang, J., Ghosh, P. (2013). Optimizing electric vehicle charging: A customer's perspective. IEEE Transactions on Vehicular Technology, 62(7), 2919-2927.

[18] Kikusato, H., Mori, K., Yoshizawa, S., Fujimoto, Y., Asano, H., Hayashi, Y., ... Suzuki, T. (2018). Electric vehicle charge-discharge management for utilization of photovoltaic by coordination between home and grid energy management systems. IEEE Transactions on Smart Grid, 10(3), 3186-3197.

[19] Chaudhari, K., Ukil, A., Kumar, K. N., Manandhar, U., Kollimalla, S. K. (2017). Hybrid optimization for economic deployment of ESS in PV-integrated EV charging stations. IEEE Transactions on Industrial Informatics, 14(1), 106-116.

[20] Office of Energy Efficiency and Renewable Energy. Global plug-in light vehicle sales increased by about 80 per cent in 2015, Fact nb 918 data sheet, US department of energy. 2016.

[21] Rasmus Luthander, Joakim Widén, Daniel Nilsson, Jenny Palm, Photovoltaic self-consumption in buildings: A review, Applied Energy, Volume 142, 2015,Pages 80-94,ISSN 0306-2619,

[22] Abdul Rauf Bhatti, Zainal Salam, A rule-based energy management scheme for uninterrupted electric vehicles charging at constant price using photovoltaic-grid system, Renewable Energy, Volume 125, 2018, Pages 384-400, ISSN 0960-1481,

[23] G. Barone, A. Buonomano, F. Calise, C. Forzano, A. Palombo, Building to vehicle to building concept toward a novel zero energy paradigm: Modelling and case studies, Renewable and Sustainable Energy Reviews, Volume 101, 2019, Pages 625-648, ISSN 13640321,

[24] Bhatt P., Long C., Saiyad M. (2020) Review of the Impact of Vehicle-to-Grid Schemes on Electrical Power Systems. In: Mehta A., Rawat A., Chauhan P. (eds) Advances in Electric Power and Energy Infrastructure. Lecture Notes in Electrical Engineering, vol 608. Springer, Singapore

[25] Ghazvini, A. M., Olamaei, J. (2019). Optimal sizing of autonomous hybrid PV system with considerations for V2G parking lot as controllable load based on a heuristic optimization algorithm. Solar Energy, $184,30-39$.

[26] Wang, Y., Infield, D. (2018). Markov Chain Monte Carlo simulation of electric vehicle use for network integration studies. International Journal of Electrical Power and Energy Systems, 99, 85-94.

[27] Nimalsiri, N., Smith, D., Ratnam, E., Mediwaththe, C., Halgamuge, S. (2020, February). A Decentralized Electric Vehicle Charge Scheduling Scheme for Tracking Power Profiles. In 2020 IEEE Power 
and Energy Society Innovative Smart Grid Technologies Conference (ISGT) (pp. 1-5). IEEE.

[28] Yao, L., Lim, W. H., Tsai, T. S. (2016). A real-time charging scheme for demand response in electric vehicle parking station. IEEE Transactions on Smart Grid, 8(1), 52-62.

[29] Tushar, W., Yuen, C., Huang, S., Smith, D. B., Poor, H. V. (2015). Cost minimization of charging stations with photovoltaics: An approach with EV classification. IEEE Transactions on Intelligent Transportation Systems, 17(1), 156-169.

[30] Badea, G., Felseghi, R. A., Varlam, M., Filote, C., Culcer, M., Iliescu, M., Răboacă, M. S. (2019). Design and simulation of romanian solar energy charging station for electric vehicles. Energies, 12(1), 74.

[31] G. Liu, Y. Xue, M. S. Chinthavali and K. Tomsovic, ”Optimal Sizing of PV and Energy Storage in an Electric Vehicle Extreme Fast Charging Station," 2020 IEEE Power and Energy Society Innovative Smart Grid Technologies Conference (ISGT), Washington, DC, USA, 2020, pp. 1-5, doi: 10.1109/ISGT45199.2020.9087792.

[32] Kikusato, H., Mori, K., Yoshizawa, S., Fujimoto, Y., Asano, H., Hayashi, Y., Suzuki, T. (2018). Electric vehicle charge-discharge management for utilization of photovoltaic by coordination between home and grid energy management systems. IEEE Transactions on Smart Grid, 10(3), 3186-3197.

[33] Odkhuu, N., Lee, K. B., A Ahmed, M., Kim, Y. C. (2018). Optimal energy management of V2B with RES and ESS for peak load minimization. Applied Sciences, 8(11), 2125.

[34] Yan, Q., Zhang, B., Kezunovic, M. (2018). Optimized operational cost reduction for an EV charging station integrated with battery energy storage and PV generation. IEEE Transactions on Smart Grid, 10(2), 2096-2106.

[35] Mouli, G. C., Bauer, P., Zeman, M. (2016). System design for a solar powered electric vehicle charging station for workplaces. Applied Energy, 168, 434-443.

[36] Van der Meer, D., Mouli, G. R. C., Mouli, G. M. E., Elizondo, L. R., Bauer, P. (2016). Energy management system with PV power forecast to optimally charge EVs at the workplace. IEEE transactions on industrial informatics, 14(1), 311-320.

[37] Tang, C., Liu, M., Liu, Q., Dong, P. (2020). A per-node granularity decentralized optimal power flow for radial distribution networks with PV and EV integration. International Journal of Electrical Power and Energy Systems, 116, 105513.

[38] Luo, L., Wu, Z., Gu, W., Huang, H., Gao, S., Han, J. (2020). Coordinated allocation of distributed generation resources and electric vehicle charging stations in distribution systems with vehicle-to-grid interaction. Energy, 192, 116631

[39] Wang, D., Locment, F., Sechilariu, M. (2020). Modelling, Simulation, and Management Strategy of an Electric Vehicle Charging Station Based on a DC Microgrid. Applied Sciences, 10(6), 2053.

[40] S. Aznavi, P. Fajri, M. B. Shadmand and A. Khoshkbar-Sadigh, Peer-to-peer Operation Strategy of PV Equipped Office Buildings and Charging Stations Considering Electric Vehicle Energy Pricing, in IEEE Transactions on Industry Applications, doi: 10.1109/TIA.2020.2990585.

[41] Luo, L., Wu, Z., Gu, W., Huang, H., Gao, S., Han, J. (2020). Coordinated allocation of distributed generation resources and electric vehicle charging stations in distribution systems with vehicle-to-grid interaction. Energy, 192, 116631.

[42] Sheng, S., Hsu, C. T., Li, P., Lehman, B. (2013, June). Energy management for solar battery charging station. In 2013 IEEE 14th Workshop on Control and Modeling for Power Electronics (COMPEL) (pp. 1-8). IEEE.

[43] Odkhuu, N., Lee, K. B., A Ahmed, M., Kim, Y. C. (2018). Optimal energy management of V2B with RES and ESS for peak load minimization. Applied Sciences, 8(11), 2125.

[44] Boudina, R., Wang, J., Benbouzid, M. et al. Impact evaluation of large scale integration of electric vehicles on power grid. Front. Energy 14, 337-346 (2020).

[45] Onar, O. C., and Khaligh, A. (2010, February). Grid interactions and stability analysis of distribution power network with high penetration of plug-in hybrid electric vehicles. In 2010 Twenty-Fifth Annual IEEE Applied Power Electronics Conference and Exposition (APEC) (pp. 1755-1762). IEEE.

[46] Li, Y., and Zhang, J. (2015, November). Research into probabilistic representation of electric vehicle's charging load and its effect to the load characteristics of the network. In 2015 5th International
Conference on Electric Utility Deregulation and Restructuring and Power Technologies (DRPT) (pp. 426-430). IEEE.

[47] Akhavan-Rezai, E., Shaaban, M. F., El-Saadany, E. F., and Zidan, A. (2012, July). Uncoordinated charging impacts of electric vehicles on electric distribution grids: Normal and fast charging comparison. In 2012 IEEE power and energy society general meeting (pp. 1-7). IEEE.

[48] Das, H. S., Rahman, M. M., Li, S., and Tan, C. W. (2020). Electric vehicles standards, charging infrastructure, and impact on grid integration: A technological review. Renewable and Sustainable Energy Reviews, 120, 109618.

[49] Honarmand, M., Zakariazadeh, A.,and Jadid, S. (2014). Optimal scheduling of electric vehicles in an intelligent parking lot considering vehicle-to-grid concept and battery condition. Energy, 65, 572-579.

[50] Houbbadi, A., Trigui, R., Pelissier, S., Redondo-Iglesias, E., and Bouton, T. (2019). Optimal scheduling to manage an electric bus fleet overnight charging. Energies, 12(14), 2727.

[51] Anand, D. M., de Salis, R. T., Cheng, Y., Moyne, J., Tilbury, and D. M. (2015). A hierarchical incentive arbitration scheme for coordinated pev charging stations. IEEE Transactions on Smart Grid, 6(4), 17751784.

[52] Škugor, B., and Deur, J. (2015). Dynamic programming-based optimisation of charging an electric vehicle fleet system represented by an aggregate battery model. Energy, 92, 456-465.

[53] Wu, Y., Ravey, A., Chrenko, D., and Miraoui, A. (2019). Demand side energy management of EV charging stations by approximate dynamic programming. Energy Conversion and Management, 196, 878-890.

[54] López, K. L., and Gagné, C. (2018, May). Optimal Scheduling for Smart Charging of Electric Vehicles Using Dynamic Programming. In Canadian Conference on Artificial Intelligence (pp. 279-284). Springer, Cham.

[55] Yao, L., Damiran, Z., and Lim, W. H. (2016, June). A fuzzy logic based charging scheme for electric vechicle parking station. In 2016 IEEE 16th International Conference on Environment and Electrical Engineering (EEEIC) (pp. 1-6). IEEE.

[56] Rahman, M. M., Al-Ammar, E. A., Das, H. S., and Ko, W. (2019). Technical Assessment of Plug-In Hybrid Electric Vehicle Charging Scheduling for Peak Reduction. In 10th international renewable energ y congress (IREC). Sousse, Tunisia: IEEE.

[57] Houbbadi, A., Trigui, R., Pelissier, S., Redondo-Iglesias, E., and Bouton, T. (2019). A quadratic programming based optimisation to manage electric bus fleet charging. International Journal of Electric and Hybrid Vehicles, 11(4), 289-307.

[58] Gao, K. Z., He, Z. M., Huang, Y., Duan, P. Y., and Suganthan, P. N. (2020). A survey on meta-heuristics for solving disassembly line balancing, planning and scheduling problems in remanufacturing. Swarm and Evolutionary Computation, 100719.

[59] Mazumder, M., and Debbarma, S. (2020). EV Charging Stations With a Provision of V2G and Voltage Support in a Distribution Network. IEEE Systems Journal.

[60] Shi, R., Li, S., Zhang, P., and Lee, K. Y. (2020). Integration of renewable energy sources and electric vehicles in V2G network with adjustable robust optimization. Renewable Energy, 153, 1067-1080.

[61] Yao, E., Wong, V. W., and Schober, R. (2016). Robust frequency regulation capacity scheduling algorithm for electric vehicles. IEEE Transactions on Smart Grid, 8(2), 984-997.

[62] S. Boyd, L. Vandenberghe and L. Faybusovich, "Convex Optimization," in IEEE Transactions on Automatic Control, vol. 51, no. 11, pp. 1859-1859, Nov. 2006, doi: 10.1109/TAC.2006.884922.

[63] J. Rivera, C. Goebel and H. Jacobsen, "Distributed Convex Optimization for Electric Vehicle Aggregators," in IEEE Transactions on Smart Grid, vol. 8, no. 4, pp. 1852-1863, July 2017, doi: 10.1109/TSG.2015.2509030

[64] W. Wei, F. Liu and S. Mei, "Charging Strategies of EV Aggregator Under Renewable Generation and Congestion: A Normalized Nash Equilibrium Approach," in IEEE Transactions on Smart Grid, vol. 7, no. 3, pp. 1630-1641, May 2016, doi: 10.1109/TSG.2015.2477844. 